\title{
Lesions of the Gum and Alveolar Bone, Due to Calculus or Other Debris, in the Golden Hamster (Cricetus auratus)
}

\author{
BY J. D. KING AND A. P. GIMSON \\ Dental Research Unit, Medical Research Council, King's College \\ Hospital Medical School, London, S.E. 5 \\ (Received 25 February 1948)
}

During the past 6 years the production of experimental 'dental caries' in the golden or Syrian hamster has been reported by a few workers (Arnold, 1942; Keyes, 1944, 1946a, $b, c$; Dale, Lazansky \& Keyes, 1944). A preliminary study of a similar nature was also begun in 1944 by one of us (J.D.K.*) and is now being continued and extended in this Unit. More recently, however, we have noted a high incidence of severe parodontal disease in hamsters receiving various stock and experimental diets. Little mention of parodontal lesions in these animals could be found in the relevant literature, although Keyes ( $1946 a$ ) noted an unspecified incidence of "gingival recession' in relation to dental caries, and the occurrence of 'periodontal pocket formation' in hamsters was given very brief mention by Mitchell (1947). Interest was particularly stimulated when our preliminary histological preparations disclosed associated deposits of dental calculus during all phases of a disease which in some respects resembled that found in the experimental ferret on bone-free diets (King, 1944 $a, b$, 1945 $d$; King \& Glover, 1945).

The present communication is largely confined to a description of the macroscopic appearance of the disease, the possible significance of the animals' salivary ducts and cheek pouches in relation to the primary lesions, and the diets on which the hamsters were fed. Details of the aetiology and histopathology will be given in a later paper.

The oral cavity of the hamster has been described by Keyes \& Dale (1944). The dentition is monophyodont, polybunodont and brachyodont, with the typical formula of rodents, $\mathrm{I} \frac{\mathrm{I}}{\mathrm{I}} \mathrm{C} \frac{0}{0} \mathrm{Pm} \frac{0}{0} \mathrm{M} \frac{3}{3}$. The incisors, growing from persistent pulps, are similar to those of the albino rat but the molar teeth have a different coronal pattern, their cusps are covered with enamel and much less inclined, and dental occlusion is effected by cuspal interdigitation. Another distinctive feature of the hamster is the presence of well-developed cheek pouches. Keyes \& Dale (1944) described them as balloon-like structures beneath the lateral dermis of the head and neck, consisting largely of fibrous elastic tissue and suspended by thin muscle strips inserted into fascia in the middorsal line. The pouches open into the mouth through the diastema between the incisor and molar teeth and are said by these authors to have no apparent digestive function or relationship to the salivary glands and teeth. Their purpose is for the

- Some preliminary work on 'dental caries' in hamsters was carried out, in association with Lady Mellanby, D.Sc., at the Nutrition Building, National Institute for Medical Research, Mill Hill. 
carrying and temporary storage of food, especially in the case of animals in the wild state. While confirming the general findings of Keyes \& Dale (1944), we are paying particular attention to the salivary ducts and cheek pouches with reference to parodontal disease in the neighbouring molar regions ( $\mathrm{Pl}$. I, figs. I-4), as noted in later paragraphs.

In general, the nutritional requirements of the hamster appear to parallel those of the white rat. Clausen \& Clark (1943) found that aneurin, nicotinic acid, riboflavin, pyridoxin and pantothenic acid were dietary essentials for maintaining growth, health and fertility, but ascorbic acid is synthesized by the animal, as in the rat. Nevertheless, it is a common experience in the maintenance of hamsters that their appetite and growth are enhanced by foods containing vitamin $\mathrm{C}$ such as cabbage, lettuce and other greenstuffs. According to the information so far available the requirements of fatsoluble vitamins and minerals are also similar to those of the albino rat.

\section{METHODS}

Thirty male hamsters were used for the work discussed here, each being placed on the experimental diet during the 7 th week of life, some 3-4 weeks after weaning. The animals were caged in pairs, although separation was sometimes necessary if they were prone to fighting or if one gained much more weight than the other. Nests of wood shavings were appreciated but in more recent experiments these were replaced by small tins, since the wood shavings appeared to have some bearing on the development and progress of parodontal lesions. The daily basal diet for each animal comprised: cereal 6-9 g., separated milk powder I g., food yeast (Torula utilis) 0.1 g., sodium chloride $0.5 \mathrm{~g}$. In addition $3 \mathrm{~g}$. of lean minced meat, and $3 \mathrm{~g}$. of fresh cabbage, were given twice weekly. Three forms of cereal were used: wholemeal flour, wheatmeal bread (crumb) and coarsely or finely ground white maize, and experimental supplements included peanut oil (free from vitamins $A$ and $D$ ), $\beta$-carotene, Radiostol (synthetic vitamin D, British Drug Houses Ltd.), and cod-liver oil, as indicated in Table r. A small quantity of water was used for mixing the dietary ingredients, which also facilitated consumption of the food by the animals.

\section{Description of lesions}

RESULTS

The parodontal disease, easily visible to the naked eye at autopsy in three-quarters of the animals after experimental periods of $19-65$ weeks, was characterized by extensive dental deposits, deep pocketing and rarefaction of the supporting tissues and marked maxillary labioversion and mandibular linguoversion of the molar teeth (Pl. 2, figs. 5-8). On the teeth and in the surrounding gum pockets were found considerable amounts of food and other debris and light or dark brown calculus (tartar). The lesions were of greatest severity in the third molar regions of the upper jaw, beginning on the labial aspects of the teeth close to the openings of the salivary ducts: The tartar accretions, at first confined to the less exposed labial grooves of the tooth crowns and closely adherent to the persisting enamel cuticle (Nasmyth's membrane) in these areas, soon began to progress along the cementum of the labial roots, 
causing inflammatory reactions in the periodontal membrane as had previously occurred in the overlying gum tissues. Rarefaction of the neighbouring alveolar crest and progressive destruction of the thinner external alveolar plate (Pl. 2, fig. $6 b, d, f$; fig. $8 b$ ) then resulted in gross labial tilting of the teeth, which in turn became still

Table I. Incidence of parodontal disease (macroscopic) in the molar regions of golden hamsters. Effect of different cereals and of varying the vitamin $A$ and vitamin $D$ content of the diet

Incidence of parodontal disease

Cereal and supplements*

Wholemeal flour (19-53 weeks):

Peanut oil

Peanut oil + radiostol

Peanut oil + carotene

Peanut oil + carotene + radiostol

Cod-liver oil

Total

Wheatmeal bread (26-65 weeks):

Peanut oil

Peanut oil + radiostol

Cod-liver oil

Total

\begin{tabular}{|c|c|c|c|c|}
\hline \multicolumn{2}{|c|}{ Animals } & \multicolumn{3}{|c|}{ Molar regions } \\
\hline $\begin{array}{c}\text { Total } \\
\text { no. }\end{array}$ & $\begin{array}{l}\text { No. with } \\
\text { lesions }\end{array}$ & $\begin{array}{c}\text { Total } \\
\text { no. }\end{array}$ & $\begin{array}{l}\text { No. with } \\
\text { lesions }\end{array}$ & $\begin{array}{c}\text { Lesions } \\
\%\end{array}$ \\
\hline
\end{tabular}

$\begin{array}{rrrrr}2 & 2 & 24 & 3 & 12 \cdot 5 \\ 2 & 1 & 24 & 6 & 25 \cdot 0 \\ 2 & 1 & 24 & 3 & 12 \cdot 5 \\ 2 & 2 & 24 & 8 & 33 \cdot 3 \\ 1 & 1 & 12 & 2 & 16 \cdot 7 \\ 9 & 7 & 108 & 22 & 20.4\end{array}$

\section{6}

5

5

16

5
$\mathbf{5}$
$\mathbf{3}$
$\mathbf{1 3}$

\section{2}

60

192

10

$$
\begin{array}{r}
25 \\
11
\end{array}
$$$$
46
$$

$24^{\circ} \mathrm{O}$

White maize (35-53 weeks):

Coarsely ground + peanut oil + carotene

Finely ground + peanut oil + carotene

Total

$\begin{array}{rrrrr}2 & 1 & 24 & 4 & 16 \cdot 7 \\ 3 & 3 & 36 & 14 & 38 \cdot 3 \\ 5 & 4 & 60 & 18 & 30 \cdot 0 \\ 30 & 24 & 360 & 86 & 23 \cdot 9\end{array}$

- Peanut oil: free from vitamins $A$ and $D, 1$ g./animal daily.

Radiostol (British Drug Houses Ltd.): 125 i.u. of vitamin D/animal daily, in Y g. of peanut oil. $\beta$-Carotene: $0.2 \mathrm{mg}$./animal daily, in I g. of peanut oil.

Cod-liver oil: 1 g./animal daily, containing approx. 700 i.u. of vitamin A and 125 i.u. of vitamin D. Food yeast (Torula utilis) of the basal diet provided the vitamins of the B complex (see p. I12).

further accentuated by the normal occlusal masticatory stresses and by the packing of more food and other debris and continued formation of calculus in the diseased regions. Indeed, we already have histological evidence that food particles and foreign bodies, including wood shavings, sawdust and hair, lacerated and penetrated the parodontal structures of these animals, as in the rat (King, 1935); but, unlike in the rat, these substances, when embedded in the diseased tissues of hamsters, were more inclined to form nidi for calculus deposition, or even to become calcified themselves. Eventually the affected upper third molar teeth of the hamsters inclined labially more than $40^{\circ}$ from their normal vertical axes and, in a few extreme cases, were exfoliated. Similar lesions were evident in the upper second molars, beginning on their buccodistal aspects but to a lesser degree, and a still smaller proportion of upper first molars was affected. One-fourth of the lower first molars also showed pocketing and 
displacement, but in this case the disease began on the lingual side and the teeth became tilted towards the tongue. The primary lesions were thus again associated with the orifices of salivary ducts which, in the lower jaw, are found near the lingual surfaces of the first molar teeth. The mandibular second molar regions were much less prone to disease and the lower third molars still less so. Varying degrees of rotation of the affected teeth were also observed.

The prevalence of the gross parodontal lesions in different teeth may be well illustrated by considering all the animals together, irrespective of their basal diets and experimental supplements. In the thirty animals discussed here there were sixty molar teeth of each type and, in order of frequency, the percentage incidence figures were as follows:

$\begin{array}{llll}\text { Upper third molars } & 66.7 & \text { Upper first molars } & 6 \cdot 7 \\ \text { Upper second molars } & 36.7 & \text { Lower second molars } & 6 \cdot 7 \\ \text { Lower first molars } & 25.0 & \text { Lower third molars } & 1 \cdot 7\end{array}$

The relative distances of the various upper and lower molar teeth from their respective maxillary and mandibular salivary duct orifices would seem to be one of the determining aetiological factors of this form of parodontal disease in the hamster as in the ferret (King, 1944a, $b, 1945 d$; King \& Glover, 1945).

\section{Dietary factors and incidence of lesions}

The influence of dietary factors on the incidence of macroscopic parodontal disease in the three series of hamsters is also best considered in terms of the percentage of molar regions affected, each of the thirty animals having twelve such regions (Table $\mathrm{I}$ ). No marked differences were apparent between the three cereal groups. The somewhat higher total figure for the white maize series may perhaps be discounted by the small number of animals surviving the experimental period. In the wholemeal flour and wheatmeal bread experiments the incidence of gross lesions was higher in the hamsters given vitamin $\mathrm{D}$, with $(33.3 \%)$ or without $(25.0$ and $4 \mathrm{I} \cdot 7 \%)$ added $\beta$-carotene. There was little difference between the peanut oil (12.5 and $13.9 \%$ ), peanut oil plus $\beta$ carotene $(12.5 \%)$ or cod-liver oil $(16.7$ and $18.3 \%$ ) groups, although the last showed rather more affected regions. On the other hand, microscopic preparations of the jaws of each of the thirty animals indicated that susceptibility to the disease was not accentuated by any one, or a combination, of the experimental supplements. Indeed, there was some evidence that the lesions were slightly retarded, but not prevented, by cod-liver oil and $\beta$-carotene. It must be stressed, however, that neither vitamin A deficiency nor rickets occurred in any of the thirty animals, these conditions being prevented respectively by the carotene-containing cabbage and by the calcium and phosphorus content of the basal diets. The vitamin additions therefore constituted dietary reinforcements of basal rations already adequate in vitamins and minerals.

As mentioned earlier, attention was given to the anatomy of the oral and related structures other than the teeth, parodontal tissues and salivary ducts, since certain differences may distinguish the hamster from other rodents. The division of the mouth cavity by cheek folds into anterior (incisor) and posterior (molar) parts was not so 
pronounced in hamsters as in rats or mice. 'This, together with the greater relative width of the head, allowed the hamster to open its mouth to a greater extent, but the most distinctive feature was the presence of cheek pouches. The filled and distended cheek pouch of a typical hamster was found to extend from the incisor-molar diastema along the external surface of the masseter muscle and beyond to the shoulder region for a distance of some $5 \mathrm{~cm}$. The vertical measurements of the cavity ranged from about $\mathrm{I} \mathrm{cm}$. at the anterior end to $\mathrm{I} \cdot 5 \mathrm{~cm}$. below the ear and $\mathrm{I} \cdot 8 \mathrm{~cm}$. posteriorly, the pouch bulging laterally according to the amount of food contained. The appearance of replete and empty cheek pouches in the same animal and the interior of a distended pouch following formol fixation and removal of its contained food and external wall are shown in Pl. 1 , figs. $1-3$; a view of the pouch opening from the lingual side, with the tongue retracted, is seen in fig. 4 . The animal impels its food from mouth to pouch by means of the tongue aided, for coarse or 'lumpy' diets, by the forepaws. Movement along the pouch, in either direction, seems to be largely governed by the contraction and relaxation of its walls, the components of which include a relatively thin mucus-moistened epithelial lining supported throughout by variable but generally thick bands of both connective (mainly elastic) tissue and muscle. Sometimes the hamsters tended to fill or use one particular pouch more than the other, but there was no evidence that this habit had a significant bearing on the relative incidence of the gross disease in the two sides of the jaws.

Examination of the anatomical relationship of the cheek pouches to the teeth on the one hand and the salivary glands on the other is still in progress. Histological and other studies of these structùres are also being undertaken, with a view to determining reasons for the apparently increased susceptibility of the golden hamster to calculus formation as compared with some other rodents.

\section{DISCUSSION}

There is need for no lengthy commentary on the findings presented here since they are essentially preliminary to the detailed investigations now in progress. It seems clear that a very severe form of parodontal disease may be induced in the golden hamster by diets containing large amounts of wholemeal flour, wheatmeal bread, or white maize, even when the basal rations, themselves nutritionally adequate for general health and reproduction, are further enriched by supplements of $\beta$-carotene, vitamin $A$ and vitamin D. The incidence of lesions obvious to the naked eye alone may reach $67 \%$ in the maxillary third molar regions. Moreover, histological examination of the animals has already indicated a much higher incidence even in the upper first and lower third molar regions which, to the naked eye, often appear relatively free from disease.

The oral lesions are primarily due to injury of the gum by salivary calculus and are subsequently accentuated by impaction of food debris and foreign bodies and by the stresses of dental occlusion. The factors influencing the gross parodontal health of the hamster thus differ to some degree from those obtaining in the albino rat (King, 1935, 1940) and have a greater tendency to resemble those observed in the ferret (King, 
r944a, $b$, 1945d; King \& Glover, 1945). However, the hamster disease shows several distinctive features:

(I) The tartar accretions, while again beginning and forming in largest amounts on those aspects of the teeth nearest to the openings of the salivary ducts, tend to develop at a greater rate than in other animals studied by us.

(2) Injury and pocketing of the gum by calculus is soon followed by impaction of food and other debris-a phenomenon not generally observed in the ferret and probably accounting for the relative absence in the hamster of the gum eversion and epithelial and connective tissue reactions characteristic of uncomplicated gingival response to tartar (King, 1944a, b, 1945a, b, $c, 1947 a, b$ ).

(3) The combined traumatic and inflammatory effects of calculus and debris impaction then initiate resorption of the inner side of the alveolar bone adjacent to the gingival lesion-labially in the upper third molar and lingually in the lower first molar regions, according to their proximity to the salivary ducts. Displacement and often rotation of the affected teeth in these directions soon follow.

(4) The normal forces of dental occlusion also take part in the disease process, their influence being directly related to the method of tooth apposition by intercuspal digitation, and to the primary disease sites in the two jaws. Thus, in the maxilla where the initial parodontal lesion is around the third molar tooth, the impact of its opposing relatively disease-free lower third molar adds further force to the labial tilting of the upper tooth already initiated by resorption of the labial alveolar bone. In the mandible where the first molar region is initially affected and where lingual alveolar resorption has begun, the occlusal impact of the comparatively disease-free upper first molar causes further displacement of its affected opponent. In both jaws, therefore, the bone resorption and tilting of the teeth, originally resulting from tartar deposits, food particles and other debris, are further accentuated by occlusal trauma. Eventually, of course, all the molar regions become markedly diseased, the lower third molar usually being the last to be grossly involved.

(5) It may also be mentioned that, in the histological study still in progress, we already have evidence of deposition of new alveolar bone next to the tooth on its less affected side-palatally in the maxilla and labially in the mandible-which adds further force to the respective labial and lingual displacement of the molar teeth.

It would thus seem that we now possess experimental analogues of parodontal disease in man arising from extraneous irritants-tartar, food particles and other debris-associated with two main types of teeth. The 'ferret disease' occurs in an animal equipped almost entirely with anterior and posterior teeth of secodont form and having a scissor-like action during mastication. With the exception of the relatively small bunodont upper first and lower second molars, occlusion in the ferret is effected between the palatal aspect of the maxillary and the labial aspect of the mandibular teeth and little lateral displacement is encountered. On the other hand, the teeth of the hamster occlude by interdigitation of the horizontal surfaces of their cusps and any parodontal disease is influenced by occlusal trauma, as outlined above. It is reasonable to suggest that the experimental lesions in these two animal species may correspond, in their aetiology and pathology, to the calculus-debris type of parodontal disease in man, 
the disease in the ferret to that commonly found in the human lower incisor region and the hamster lesions to those in the human upper first molar region. In all three species proximity of the initial disease sites to the openings of the salivary ducts is certainly a common aetiological factor. These apparent similarities are being explored further with particular reference to the possibility that labial bone resorption and subsequent labioversion and torsion of the upper first molar, accentuated by interdigital occlusion with its frequently tartar-free mandibular opponent, may also occur in man. The close resemblance of the ferret lesions to disease in the incisor part of the human lower denture has already been demonstrated by clinical observation, biopsy examinations and capillary microscopy in vivo (King, 1945a,b,c, 1947a, b). If a corresponding relationship were found to exist between the hamster and man in respect of the molar areas, our knowledge of the pathology of this form of parodontal disease might be further advanced.

At the present stage, methods of preventing or curing the lesions in the hamster have not been established. In view of the value of gnawing bone as a prophylactic and curative factor in the disease of the ferret and of somewhat similar findings in man as a result of gnawing sugar cane (King, $1947 b, c$ ), it would seem likely that some form of frictional prophylaxis or treatment may prove effective for preventing and eliminating the lesions in the hamster. This and other associated problems are under investigation and any conclusive findings will be reported at a later date.

\section{SUMMARY}

1. The macroscopic appearances are described of a severe form of parodontal disease in thirty golden hamsters fed on diets containing large amounts of wholemeal flour, wheatmeal bread or white maize. Additions of $\beta$-carotene, vitamin $\mathrm{D}$ and codliver oil to the basal rations appeared to have little bearing on the disease. Those animals receiving vitamin $\mathrm{D}$, in the form of Radiostol (British Drug Houses Ltd.), tended to show a rather higher incidence of the gross lesions, but this difference has not so far been confirmed by microscopic preparations.

2. The disease is primarily due to injury of the parodontal structures by salivary calculi and is accentuated by impaction of food particles and other debris and by the stresses of dental occlusion. The calculus deposits and parodontal lesions arise and are most extensive in those areas of the teeth in close proximity to the orifices of the salivary ducts.

3. Various aspects of the syndrome in the hamster are discussed with special reference to their possible relationship to parodontal disease in the ferret and in man.

\section{REFERENCES}

Arnold, F. A. (1942). Publ. Hlth Rep., Wash., 57, 1599.

Clausen, D. F. \& Clark, W. G. (1943). Nature, Lond., r52, 300.

Dale, P. P., Lazansky, J. P. \& Keyes, P. H. (1944). F. dent. Res. 23, 427.

Keyes, P. H. (1944). F. dent Res. 23, 439.

Keyes, P. H. (1946a). F. dent. Res. 25, 341.

Keyes, P. H. (1946b). F. Nutrit. 32, 525.

Keyes, P. H. $(1946 c)$. F. dent. Res. 25, 469. 
Keyes, P. H. \& Dale, P. P. (1944). F. dent. Res. 23, 445.

King, J. D. (1935). Dent. Rec. 55, 522.

King, J. D. (1940). Brit. dent. F. 68, 349.

King, J. D. (1944a). Brit. dent. F. 77, 213.

King, J. D. (I944b). Brit. dent. F. 77, 245.

King, J. D. (r945a). Dent. Rec. 65, 9.

King, J. D. (1945b). Dent. Rec. 65, 32.

King, J. D. (1945c). Dent. Rec. 65, 55 .

King, J. D. (1945d). Nature, Lond., 156, 572.

King, J. D. (1947a). Dent. Rec. 67, 3.

King, J. D. (1947b). Brit. dent. $¥ .82,61$.

King, J. D. (1947c). Brit. med. $\mathcal{F}$. ii, 987 .

King, J. D. \& Glover, R. E. (1945). F. Path. Bact. 57, 353.

Mitchell, D. F. (1947). F. dent. Res. 26, 457.

\section{EXPLANATION OF PLATES}

Platr 1. Photographs of the hamster's cheek pouches

Fig. I (natural size). Shows one filled and one empty pouch.

Fig. 2 (natural size). Lateral view of the filled pouch seen in fig. 1. Dotted line indicates approximate limits of pouch cavity.

Fig. 3 (magn. $\times 3$ ). Pouch of same animal with contents and external wall removed. Note stippled appearance of pouch lining similar to that of mucous membrane of mouth. The tongue $(T)$ can be seen protruding beyond the oral opening of the pouch.

Fig. 4 (magn. $\times 3$ ). Lingual view of pouch opening, indicated by dotted line, with tongue retracted to expose the mandibular tecth of one side. Note parodontal disease $(P)$ in first molar region.

Plate 2. Photographs $(\times 6)$ and radiographs $(\times 6)$ of the molar regiens of hamsters showing different stages of parodontal disease

Fig. 5. Palatal view of upper teeth on one side of a hamster with beginning disease in the third molar region. This animal is not included in Table $\mathrm{I}$, having died before the $\mathrm{I}$ oth week of experimental feeding, but is shown here to indicate early maxillary lesions.

Fig. 6a. Palatal view of moderately advanced phase of disease in upper left regions with parodontal pocketing, calculus and debris around second and third molars, both of which are displaced labially. There is also beginning involvement of the first molar, particularly on its distal side. Experimental period, 19 weeks. $b$. Radiograph of area seen in fig. $6 a$, showing resorption of alveolar bone in second and third molar regions and extending to distal root of first molar. c. Palatal view of upper teeth on opposite side of jaw of same animal again showing parodontal lesions, calculus and debris in second and third molar regions with labial tooth displacement. Torsion of the third molar is also evident. $d$. Radiograph of area seen in fig. $6 c$, showing similar conditions to those of opposite side. e. Labial view of tissues seen in fig. $6 a$, showing marked calculus formation (especially on the third molar), parodontal pocketing with gum recession, and displacement of the two posterior teeth. f. Radiograph of area shown in fig. $6 e$ and of the same region as fig. $6 b$ but taken from the labial aspect. Bone resorption in the second and third molar regions is clearly visible.

Fig. $7 a, b$. Photograph and radiograph of the lingual aspect of a hamster's lower molar regions, following dieting for the same period ( 19 weeks) as that of the animal shown in figs. $6 a-f$. Note absence of gross parodontal changes.

Fig. $8 a, b$. Photograph and radiograph of lower molar regions of another hamster after an experimental period of 64 weeks. Note parodontal pocketing on distal aspect of the first molar tooth, which also shows beginning lingual displacement, but conditions are less severe than those seen in upper jaws of animals on much shorter experimental periods (cf. figs. $6 a-f$ ).

$$
M_{1}=\text { first molar. } M_{2}=\text { second molar. } \quad M_{3}=\text { third molar. }
$$


British Fournal of Nutrition, Vol. 2, No. 2

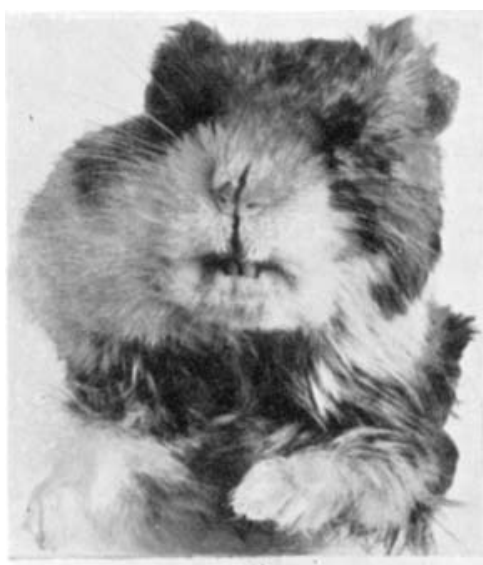

1

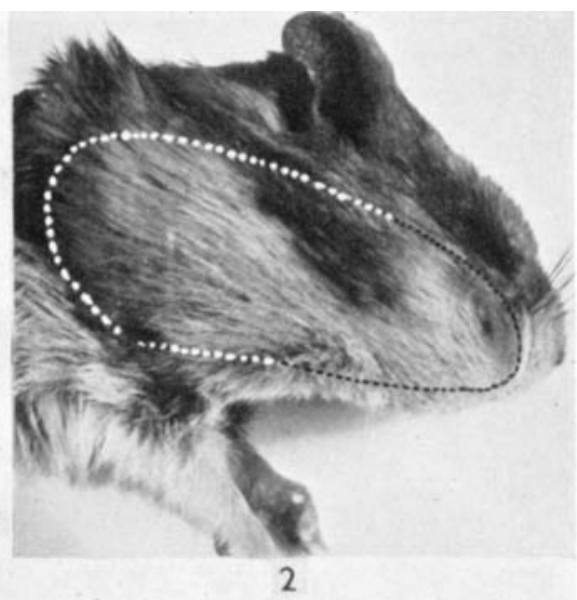

2

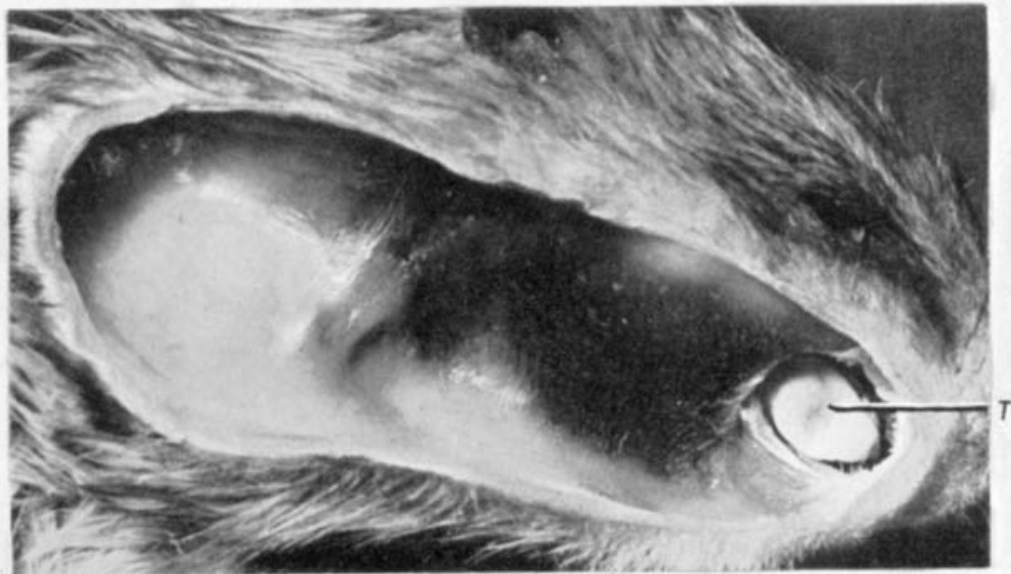

3

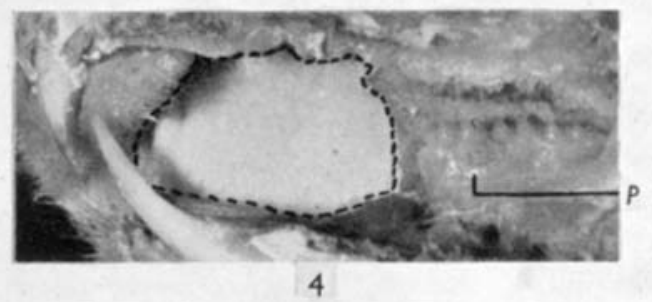

Figs. 1-4 
British Fournal of Nutrition, Vol. 2, No. 2

Plate 2
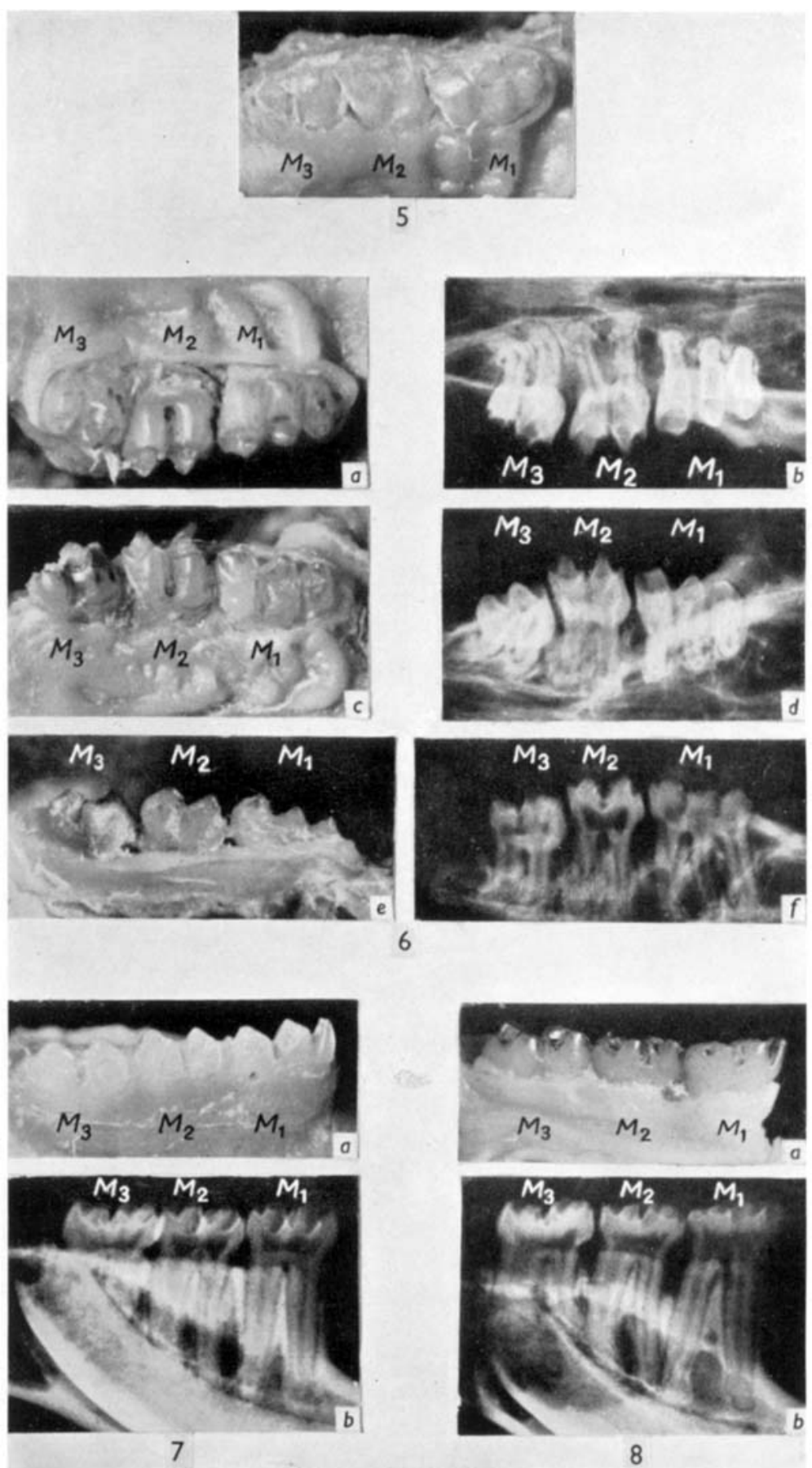

Figs. $5^{-8}$ 